\title{
Auditory Priming within and across Modalities: Evidence from Positron Emission Tomography
}

\section{Citation}

Badgaiyan, Rajendra D., Daniel L. Schacter, and Nathaniel M. Alpert. 1999. Auditory priming within and across modalities: Evidence from positron emission tomography. Journal of Cognitive Neuroscience 11(4): 337-348.

\section{Published Version}

doi:10.1162/089892999563463

\section{Permanent link}

http://nrs.harvard.edu/urn-3:HUL.InstRepos:3627268

\section{Terms of Use}

This article was downloaded from Harvard University's DASH repository, and is made available under the terms and conditions applicable to Other Posted Material, as set forth at http:// nrs.harvard.edu/urn-3:HUL.InstRepos:dash.current.terms-of-use\#LAA

\section{Share Your Story}

The Harvard community has made this article openly available.

Please share how this access benefits you. Submit a story.

Accessibility 


\title{
Auditory Priming within and across Modalities: Evidence from Positron Emission Tomography
}

\author{
Rajendra D. Badgaiyan \\ Harvard University and Massachusetts General Hospital
}

\author{
Daniel L. Schacter
}

Harvard University

Nathaniel M. Alpert

Massachusetts General Hospital

\begin{abstract}
Previous neuroimaging studies of perceptual priming have reported priming-related decreases in the extrastriate cortex. However, because these experiments have used visual stimuli, it is unclear whether the observed decreases are associated specifically with some aspect of visual perceptual processing or with more general aspects of priming. We studied withinand cross-modality priming using an auditory word stem completion paradigm. Positron emission tomography (PET) images were obtained during stem completion and a fixation task. Within-modality auditory priming was associated with blood
\end{abstract}

\section{INTRODUCTION}

Priming refers to a change in the ability to identify or produce an object or word as a result of a specific prior encounter with the item (Tulving \& Schacter, 1990). Priming does not require conscious or explicit recollection of a prior encounter with an object and is thus considered a form of nonconscious, nondeclarative, or implicit memory (cf. Jacoby, Toth, \& Yonelinas, 1993; Schacter, Chiu, \& Ochsner, 1993; Squire, 1994).

A variety of recent studies have examined priming using functional neuroimaging techniques such as positron emission tomography (PET) and functional magnetic resonance imaging (fMRI). Such studies have consistently shown that priming is accompanied by reduced activity in a variety of cortical regions (for review, see Schacter \& Buckner, 1998; Wiggs \& Martin, 1998). One of the most consistent findings has been reported in studies using a word stem completion paradigm: after studying a list of words, subjects are later shown three-letter word stems and are asked to provide the first word that comes to mind. Priming occurs when participants produce more designated target items to stems of flow decreases in the extrastriate cortex (bilateral), medial/ right anterior prefrontal cortex, right angular gyrus, and precuneus. In cross-modality priming, the study list was presented visually, and subjects completed auditory word stems. Crossmodality priming was associated with trends for blood flow decreases in the left angular gyrus and increases in the medial/right anterior prefrontal cortex. Results thus indicate that reduced activity in the extrastriate cortex accompanies withinmodality priming in both visual and auditory modalities.

previously studied words than to stems of nonstudied words. Several studies have reported reduced activity in regions of the extrastriate visual cortex, most notably Brodmann's area (BA) 19, during primed stem completion performance compared to unprimed stem completion performance (Backman et al., 1997; Buckner et al., 1995; Schacter et al., 1996; Squire et al., 1992; for related data with event-related potentials, see Badgaiyan \& Posner, 1996; 1997). Priming-related reductions in this region have also been observed for other priming tasks involving both words and objects (e.g., Blaxton et al., 1996; Buckner et al., 1998).

The results of previous studies support the idea that priming-related blood flow decreases in the extrastriate cortex reflect modality-specific reductions in visual operations: encoding of visual features of target items during the study phase may facilitate later visual processing of test stems. However, prior neuroimaging studies of perceptual priming have used visual stimuli (for a related study of item repetition effects using auditory stimuli, see Buckner, Koutstaal, Schacter, \& Rosen, 1999). It is therefore unclear whether priming-related decreases in the extrastriate cortex are associated specifically with 
some aspect of visual perceptual processing or with more general aspects of priming. To illuminate the matter, it would be desirable to use neuroimaging techniques to investigate forms of priming that do not require visual processing. Auditory priming represents a promising target for such investigations.

Previous behavioral studies have reported reliable priming effects in auditory stem completion tasks, where participants hear the first syllable of a word and respond with the first word that comes to mind (Bassili, Smith, \& MacLeod, 1989; Church \& Schacter, 1994; Schacter \& Church, 1992). Such studies have also shown that auditory stem completion priming is greater when the study and test items are presented in the same modality (within-modality priming) than in different modalities (cross-modality priming; Bassili et al., 1989; McClelland \& Pring, 1991).

To help extend the domain of priming and neuroimaging research beyond the visual modality, and to provide a broader basis for interpreting previous observations of priming-related reductions in the extrastriate cortex, we performed two PET studies of auditory priming. Experiment 1 examined within-modality auditory priming. If previous observations of priming-related decreases in the extrastriate cortex reflect modality-specific visual processing, no such reductions should be observed during auditory priming. If, on the other hand, these decreases are associated with more general priming processes that are not specific to the visual modality, priming-related extrastriate decreases may be observed during auditory priming. In addition, in view of prior suggestions that auditory priming may depend on cortical regions subserving auditory processing (e.g., Schacter, 1994), priming-related decreases in the auditory cortex would also be expected.

Experiment 2 included a cross-modality priming condition. If priming-related decreases in the extrastriate cortex reflect very general changes, they may also be observed during cross-modality priming. However, previous evidence from both cognitive studies (e.g., Kirsner, Dunn, \& Standen, 1989; Jacoby et al., 1993; Richardson-Klavehn \& Gardiner, 1996) and neuropsychological investigations (e.g., Curran, Schacter, \& Galluccio, 1999) suggests that different mechanisms underlie within- and cross-modality priming on the stem completion task. More specifically, it has been suggested that cross-modality priming is mediated by (1) some form of abstract lexical representation involved in phonological input or output processing (e.g., Curran et al., 1999; Kirsner et al., 1989; Weldon, 1991) and (2) aspects of explicit retrieval (Jacoby et al., 1993; Richardson-Klavehn \& Gardiner, 1996). Although these issues have not been examined previously in neuroimaging studies, we were particularly interested in the possibility that regions previously implicated in phonological processing and explicit retrieval would be associated with cross-modality priming.
In Experiment 2, subjects completed auditory stems following auditory study of some words and visual study of others. We used experimental conditions that produced similar levels of within- and cross-modality priming (see Methods), thereby allowing a direct comparison between the two forms of priming that is not confounded by overall differences in the amount of priming observed. To facilitate comparison across experiments, we describe Methods and Results for the two experiments together.

\section{RESULTS}

\section{Experiment 1}

Analysis of behavioral data revealed a significant priming effect. Collapsed across test blocks, subjects completed $49.2 \%$ of primed stems using studied words, compared to $16.4 \%$ in the baseline condition $(t(7)=12.42, p<$ 0.0001 ). The levels of priming (as indicated by priming scores obtained by subtracting baseline stem completion rates from primed stem completion rates) showed no consistent trend across study-test blocks. Compared to the first study-test block, priming scores did not differ significantly in the second $(t(7)=1.83 ; p>0.11)$ or third $(t(7)=1.07 ; p>0.32)$ study-test blocks (Table 1 ).

The fact that similar amounts of priming were observed across study-test blocks suggests that the subjects did not engage in intentional or explicit retrieval strategies during the stem completion task. Such a strategy would have inflated priming scores in the second and third blocks.

Compared to the fixation control, baseline auditory stem completion performance produced $\mathrm{rCBF}$ increases in a network of left-hemisphere regions: the primary

Table 1. Behavioral Responses for Within- and Cross-Modality Priming Conditions in Different Study-Test Blocks

\begin{tabular}{|c|c|c|c|}
\hline & Block 1 & Block 2 & Block 3 \\
\hline \multicolumn{4}{|c|}{ Experiment 1} \\
\hline \multicolumn{4}{|l|}{ Within-modality priming } \\
\hline Priming score (\%) & 32.0 & 36.5 & 29.8 \\
\hline Response latency (msec) & 1931 & 1899 & 1860 \\
\hline \multicolumn{4}{|c|}{ Experiment 2} \\
\hline \multicolumn{4}{|l|}{ Within-modality priming } \\
\hline Priming score (\%) & 34.9 & 33.1 & - \\
\hline Response latency (msec) & 1866 & 1829 & - \\
\hline \multicolumn{4}{|l|}{ Cross-modality priming } \\
\hline Priming score (\%) & 28.3 & 29.9 & - \\
\hline Response latency (msec) & 1862 & 1784 & - \\
\hline
\end{tabular}

Priming score $=$ percentage of correct stem completions for primed words minus percent of correct completions for baseline words. 
auditory cortex (BA 41), auditory association cortex including BA 42 and Wernicke's area (BA 22), and inferior frontal cortex (Broca's area, BA 44; see Table 2). Increases in the left primary auditory cortex and Broca's area are consistent with the role of these areas in auditory processing and speech production, respectively (for recent neuroimaging evidence see Binder, 1997; Price et al., 1996; Strainer et al., 1997; for discussion of related cognitive functions see Abdullaev, Bechtereva, \& Melnichuk, 1998). Activation of the left auditory association cortex is also consistent with its involvement in speech processing and comprehension (for relevant neuroimaging data, see Berry et al., 1995; Strainer et al., 1997). No areas showed significant decreases in the baseline condition compared to the fixation condition.

In the priming condition, the primary auditory cortex and Broca's area showed significant increases compared to fixation. Because the priming condition, like the base- line condition, also involved auditory processing of the word stem and speech production, these activations are not unexpected. In addition to these activations, three regions showed decreased regional cerebral blood flow (rCBF) in priming compared to fixation: the precuneus, medial prefrontal cortex extending into right anterior prefrontal cortex, and bilateral extrastriate cortex (BA 19). Critically, comparison of the priming and baseline auditory stem completion conditions (Table 2) revealed priming-related decreases in these regions, as well as in right angular gyrus. Note also that in contrast to the significant activation in the auditory association cortex during baseline stem completion compared to fixation, there was no comparable activation during primed stem completion compared to fixation. Such a pattern suggests that the contributions of the auditory association cortex to stem completion performance may have been influenced by priming, and there was a trend $(z=2.0)$

Table 2. Regions Showing Significant rCBF Changes during Within-Modality Priming in Experiments 1 and 2

\begin{tabular}{|c|c|c|}
\hline \multicolumn{3}{|c|}{ Talairach coordinates } \\
\hline \multicolumn{3}{|c|}{ Experiment 1. Baseline Minus Fixation } \\
\hline \multicolumn{3}{|l|}{ rCBF increases } \\
\hline 1. Broca's area (BA 44) & $-34,-4,32$ & 4.94 \\
\hline 2. BA 41 + Wernicke's area (BA 22) & $-48,-40,12$ & 4.25 \\
\hline 3. BA $41+$ Aud. Ass. Cortex (BA 42) & $-64,-16,4$ & 4.69 \\
\hline \multicolumn{3}{|c|}{ Experiment 1. Priming Minus Fixation } \\
\hline \multicolumn{3}{|l|}{$\mathrm{rCBF}$ increases } \\
\hline 1. Broca's area (BA 44) & $-44,10,32$ & 4.12 \\
\hline 2. Primary Auditory Cortex (BA 41) & $-34,-44,12$ & 5.56 \\
\hline \multicolumn{3}{|l|}{ rCBF decreases } \\
\hline 1. Precuneus (BA 7) & $0,-58,44$ & 7.00 \\
\hline 2. Prefrontal cortex (BA 10/11) & $4,42,-12$ & 5.81 \\
\hline 3. Extrastriate cortex (BA 19) & $40,-84,0$ & 4.50 \\
\hline 4. Extrastriate cortex (BA 19) & $-44,-74,32$ & 3.88 \\
\hline \multicolumn{3}{|c|}{ Experiment 1. Priming Minus Baseline } \\
\hline \multicolumn{3}{|l|}{ rCBF decreases } \\
\hline 1. Extrastriate cortex (BA 19) & $40,-80,4$ & 5.06 \\
\hline 2. Extrastriate cortex (BA 19) & $-44,-82,4$ & 3.40 \\
\hline 3. Angular gyrus (BA 39/40) & $50,-66,28$ & 4.81 \\
\hline 4. Precuneus (BA 7) & $2,-62,48$ & 5.56 \\
\hline 5. Prefrontal cortex (BA 10) & $26,62,12$ & 5.75 \\
\hline \multicolumn{3}{|c|}{ Experiment 2. Priming Minus Baseline } \\
\hline \multicolumn{3}{|l|}{ rCBF decreases } \\
\hline 1. Extrastriate cortex (BA 19) & $38,-76,4$ & 3.19 \\
\hline 2. Extrastriate cortex (BA 19) & $-28,-84,4$ & 4.37 \\
\hline 3. Angular gyrus (BA 39/40) & $48,-58,28$ & 4.44 \\
\hline 4. Precuneus (BA 7) & $26,-42,52$ & 3.37 \\
\hline 5. Prefrontal cortex (BA 10) & $18,66,12$ & 4.94 \\
\hline
\end{tabular}


for reduced $\mathrm{rCBF}$ in primed compared to unprimed stem completion performance. Nonetheless, the failure to observe a significant decrease in the direct comparison between primed and baseline stem completion performance indicates that these findings must be viewed cautiously.

Finally, there were no significant $\mathrm{rCBF}$ increases in the primed stem completion condition compared to the baseline stem completion condition.

\section{Experiment 2}

In the within-modality priming condition, subjects completed $54.3 \%$ of stems using studied words, compared to $20.3 \%$ in the baseline condition ( $\mathrm{t}(7)=15.4 ; p<0.0001$ ). Further, response latencies were significantly shorter for primed words (1848 $\pm 78 \mathrm{msec}$ ) compared to baseline words $(2073 \pm 74 \mathrm{msec} ; t(7)=3.58 ; p<0.009)$. In the cross-modality condition, subjects completed $48.1 \%$ of stems using studied words, compared to $19.1 \%$ in the baseline condition $(t(7)=17.38 ; p<0.0001)$. Mean response latency in the priming condition $(1823 \pm 69$ msec) was significantly less than that in the baseline $(1995 \pm 51 \mathrm{msec} ; t(7)=2.67 ; p<0.03)$. There were no effects of test block on proportions of stems completed in either within-modality $(t(7)=0.22 ; p>0.83)$ or cross-modality $(t(7)=1.48 ; p>0.18)$ conditions. Although there was a slight trend for more priming in the within-modality than the cross-modality condition, the percentage of stems completed with target words did not differ significantly between the two conditions $(t(7)=0.27 ; \mathrm{p}>0.79)$.

Changes in rCBF were examined separately for withinand cross-modality priming conditions. We hypothesized that within-modality priming would be accompanied by rCBF decreases in the same anatomic regions observed in Experiment 1. Consistent with this hypothesis, rCBF changes were essentially identical to those observed in Experiment 1 (Table 2; Figure 1A and B). Each of the cortical regions that showed $\mathrm{rCBF}$ decreases in the primed stem completion condition compared to the baseline stem completion condition of Experiment 1 also showed reduced activity in the corresponding comparison of the present experiment: the extrastriate cortex bilaterally, right angular gyrus, precuneus and medial/right anterior prefrontal cortex.

In cross-modality priming, no areas showed increases or decreases in the priming condition compared to the baseline condition that met our statistical threshold for nonplanned comparisons ( $z=4.2$; see Methods). There were, however, several rCBF differences between the priming and baseline conditions that were at or near our threshold for planned comparisons $(z=3.09)$ and that are consistent with the hypotheses discussed in the Introduction that changes in phonological processing and explicit retrieval, respectively, play a role in crossmodal priming. We thus tentatively characterize these findings (Figures 2 and 3 ) as suggestive trends that merit further exploration in future research. First, the crossmodality priming condition was associated with an $\mathrm{rCBF}$ increase encompassing medial and right anterior prefrontal cortex (BA 10). As illustrated in the two slices shown in Figure 2, the maximum activation occurred in the medial prefrontal cortex $(0,48,20 ; z=3.31)$; the maximum activation in the right anterior prefrontal cortex was at $36,60,8 ; z=3.06$. Previous neuroimaging studies have implicated the right anterior prefrontal cortex in aspects of explicit retrieval (e.g., Tulving et al., 1994). We also observed a trend for decreased rCBF in the left angular gyrus during cross-modality priming compared to baseline (BA 39/40, -40, -46, 28; $z=3.75$; see Figure 3), a region that has been implicated previously in aspects of phonological processing (e.g., Paulesu, Frith, \& Frackowiak, 1993). Direct comparison
Figure 1. Within-modality auditory priming: Statistical parametric maps (SPM) showing significant $\mathrm{rCBF}$ decreases in the extrastriate (BA 19) and medial prefrontal (BA 10) areas during within-modality auditory priming as compared to the stem completion baseline in Experiment 1 (A) and Experiment 2 (B). The medial prefrontal activation extended to the right anterior prefrontal cortex in both experiments. The maps are superimposed over averaged structural MRI images that were transformed to Talairach space. Atlas coordinates are provided in Table 2 .

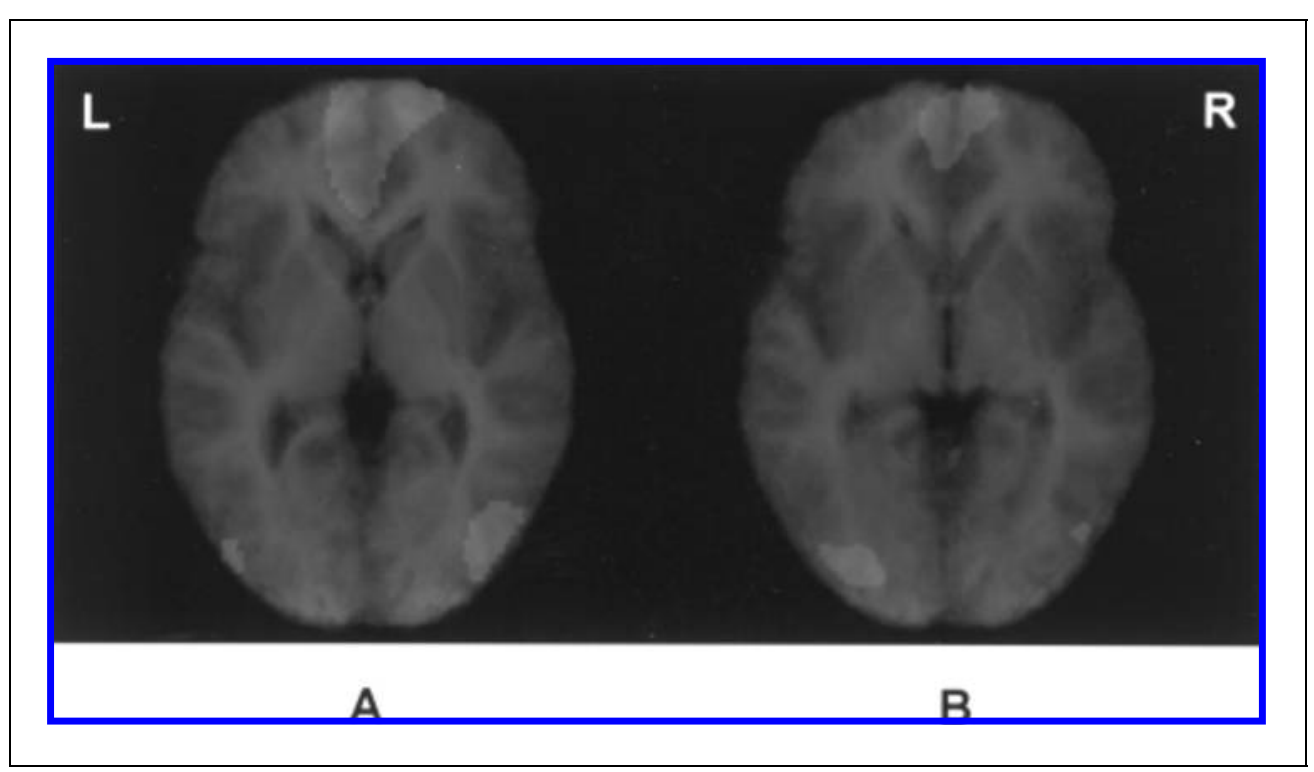


Figure 2. Cross-modality priming: SPM at two slice locations showing increased blood flow in the prefrontal cortex (BA 10) during crossmodality auditory priming (as compared to stem completion baseline). Maximal rCBF increases were observed in the medial prefrontal area $(\mathrm{A} ; \boldsymbol{z}=$ 3.31) and in the right anterior prefrontal area $(\mathrm{B} ; z=3.06)$. The maps are superimposed over averaged structural MRI images that were transformed to Talairach space.

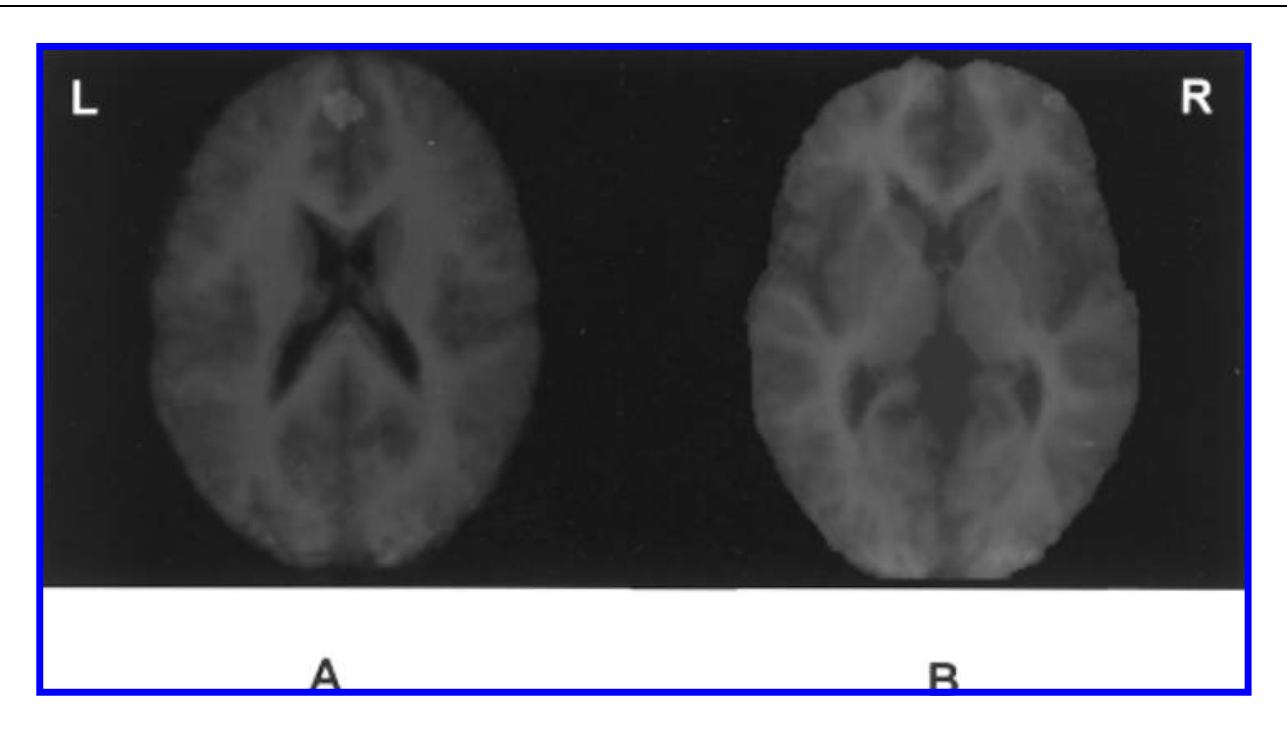

of the PET data obtained during within- and crossmodality priming also yielded findings that are best characterized as suggestive. There were trends for withinmodality $>$ cross-modality $\mathrm{rCBF}$ differences in the left angular gyrus $(-40,-46,28 ; z=3.18)$ and trends for cross-modality $>$ within-modality priming in precuneus $(10,-62,44 ; z=2.88)$ and in the right prefrontal (16, $60,16 ; z=2.94)$ and left extrastriate $(-28,-70,20 ; z=$ 2.81) cortices.

\section{DISCUSSION}

Analysis of the PET data revealed that for within-modality priming, there was reduced $\mathrm{rCBF}$ in the extrastriate area (BA 19) during primed auditory stem completion compared to baseline auditory stem completion (Experiments 1 and 2). Findings concerning cross-modality priming were less clear-cut, but the data are consistent with the possibility that cortical areas associated with cross-modality priming may be distinct from those associated with within-modality priming (Experiment 2).

The fact that we observed decreased $\mathrm{rCBF}$ in the extrastriate cortex during within-modality auditory priming in both Experiments 1 and 2 indicates that this finding is reliable and reproducible. The extrastriate region showing priming-related decreases in the present study is generally similar to that reported previously in within-modality visual stem completion priming experiments (Backman et al., 1997; Buckner et al., 1995; Schacter et al., 1996). It is also worth noting that Buckner et al. observed priming-related decreases in the extrastriate cortex during within-modality visual priming both when the type case of target items (upper or lower) was identical at study and test (same case condition) and when it differed (different case condition). The fact that Buckner et al. (1995) observed rCBF decrease in the extrastriate cortex in the different case condition sug- gests that this decrease probably does not reflect priming of the specific visual features of previously studied target words. Our findings are thus consistent with those of Buckner et al. However, because within-modality auditory priming does not require any visual perceptual processing, whereas previous discussions of primingrelated blood flow reductions in the extrastriate cortex have emphasized modality-specific perceptual processes (Buckner et al., 1995; Schacter et al., 1996; Squire et al., 1992), our findings cast new light on the mechanism involved. We consider three potential explanations to account for the rCBF decrease in the extrastriate cortex

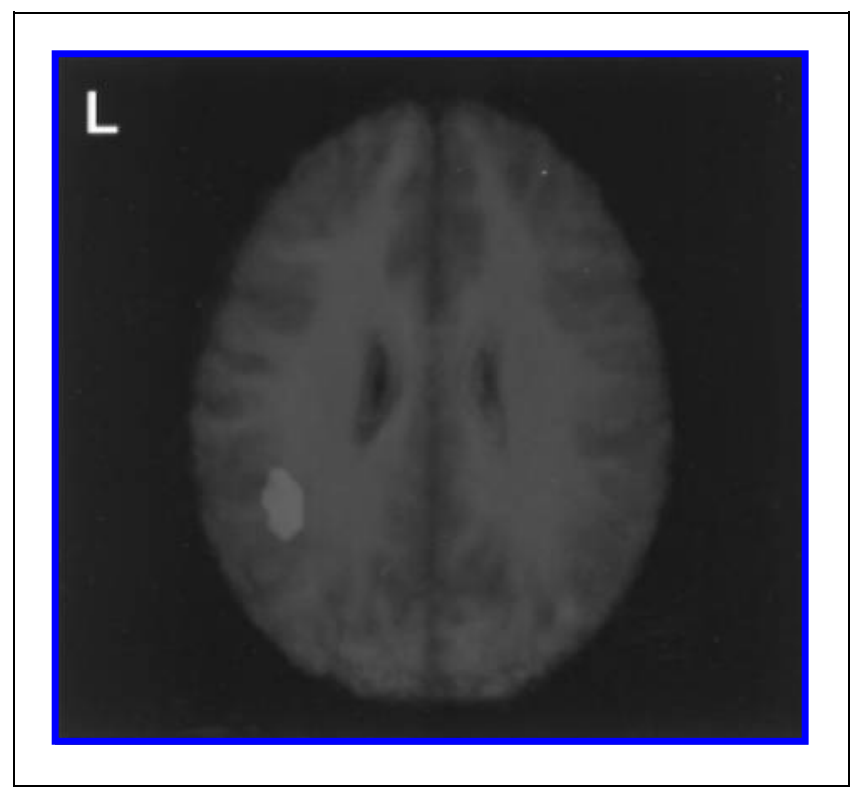

Figure 3. Cross-modality priming: SPM showing rCBF decrease $(z=$ 3.75 ) in the left angular gyrus (BA 39/40) during cross-modality priming as compared to the baseline. The maps are superimposed over averaged structural MRI images that were transformed to Talairach space. 
during auditory priming: (1) visual imagery or related processes played a role in auditory stem completion priming, (2) the decreases may reflect a kind of crossmodal suppression effect, and (3) a part of the extrastriate cortex may support nonvisual functions.

One possible account of our results involves the use of visual imagery. Neuroimaging studies have consistently reported increased $\mathrm{rCBF}$ in the extrastriate cortex (and several other cortical regions) in tasks that require visual imagery (e.g., Cabeza et al., 1997; Cohen et al., 1996; D'Esposito et al., 1997; Fletcher et al., 1995; Roland, Eriksson, Stone-Elander, \& Widen, 1987). Perhaps subjects created visual images of auditorily presented words during the study task and retrieved those images during primed auditory stem completion performance. However, by this account we should have observed increased $\mathrm{rCBF}$ - not decreased $\mathrm{rCBF}$ - in the extrastriate cortex during auditory priming. Moreover, when subjects were explicitly shown visual words during the study phase in Experiment 2, we failed to observe subsequent $\mathrm{rCBF}$ changes in the extrastriate cortex during cross-modality auditory priming. Thus, use of visual imagery during the study task and priming test does not offer a promising or even a plausible account of our results.

An alternative version of an imagery hypothesis would hold that subjects created visual images of the target words during baseline auditory stem completion performance. During primed auditory stem completion performance, however, participants may have been able to process auditory information more easily than in the baseline condition and were thus less likely to engage in visualization of target stems or words, thereby resulting in extrastriate rCBF decreases. By this view, the extrastriate cortex should have been associated with significant rCBF increases during baseline stem completion performance compared to the fixation control (possibly reflecting the occurrence of visual imagery). However, no such increases were observed. A related idea is that auditory processing may have activated orthographic features of target items during baseline stem completion performance (e.g., Tanenhaus, Flanagan, \& Seidenberg, 1980). If the extrastriate cortex is involved with orthographic processing and representation (e.g., Petersen, Fox, Snyder, \& Raichle, 1990), the observed rCBF decreases may reflect corresponding decreases in orthographic processing after auditory priming. Though an attractive idea, as with the visual imagery hypothesis, this notion would lead us to expect increased extrastriate activation in the baseline stem completion task relative to fixation.

A second hypothesis is that extrastriate decreases may reflect a suppression of visual processing during auditory task performance. For example, Buckner, Raichle, Miezin, and Petersen (1996) reported rCBF decreases in the extrastriate cortex during an auditory paired-associate recall task compared to a fixation control. In this task, subjects were presented with a cue word auditorily and were asked to recall the second member of the pair; the two words had been presented together auditorily prior to scanning. Buckner et al. suggested that the extrastriate decreases might have occurred because attention to auditory stimuli suppressed activity in visual areas (see Haxby et al., 1994, for discussion of a similar cross-modal suppression effect in the auditory cortex during visual attention).

We cannot rule out the possibility that cross-modal suppression is involved in the extrastriate decrease we observed. Nonetheless, it seems an unlikely explanation because we did not observe significant extrastriate rCBF decreases in the baseline auditory stem completion condition compared to fixation (nor did we observe any trends for such decreases, even when the significance level was set at $z=1$ ). If the observed decrease resulted from suppression of visual regions as a consequence of attention to auditory stimuli, the effect should have been observed in the baseline condition as well as in the priming condition. More generally, as Buckner et al. (1999) note, it is important to distinguish between regions that show decreased activity compared to a fixation control (for review, see Shulman et al., 1997) and decreases as a result of priming that reflect reduced activity in a region that shows increased activity during baseline task performance. The extrastriate decrease reported here is both similar to and different from each of these types of decreases. On the one hand, the extrastriate decrease was not observed during baseline stem completion performance relative to fixation (thus distinguishing it from the general kinds of decreases reviewed by Shulman et al. that occur in relation to fixation). However, it was observed in the comparison of primed and unprimed stem completion performance (similar to previous priming studies) and in the comparison of primed stem completion and the fixation condition. But whereas some previous reports of priming-related extrastriate decreases during visual stem completion have shown increased activity in this region during baseline stem completion performance compared to fixation (e.g., Buckner et al., 1995), we did not observe such an outcome (nor did Backman et al., 1997).

In the present study, reduced $\mathrm{rCBF}$ during priming both in comparison with the fixation condition and with the unprimed stem completion baseline suggests that the reduction is associated with priming and is not a result of increased $\mathrm{rCBF}$ in the unprimed stem completion baseline condition. Increased rCBF both in the fixation and the stem completion baseline condition could also produce this result, but this is unlikely because the priming task (as well as the stem completion baseline task) included the fixation condition (that is, subjects always looked at a fixation cross; this strategy helped us reduce artifacts due to eye movements, and its effects should have subtracted out in the various contrasts we 
used in this experiment). Therefore, a "fixation-related increase" should have yielded increased $\mathrm{rCBF}$ in the priming condition (rather than decreased rCBF). Clearly, however, further studies are necessary for better understanding of the significance of this reduction.

A third possible interpretation of the priming-related extrastriate decrease is that parts of the extrastriate cortex may support nonvisual functions. Neuroanatomical and electrophysiological data suggest that the extrastriate cortex in humans and other primates includes distinct areas of specialization (DeYoe et al., 1996; Rodman \& Moore, 1997; Zilles \& Clarke, 1997). A region of the extrastriate cortex (V3A) that corresponds roughly to the superolateral part of BA 19 in the human brain differs from the rest of the extrastriate cortex in its connectivity, neurohumoral profile, and cytoarchitecture (for detailed discussion, see Zilles \& Clarke). This region is extensively connected to the subcortical and cortical areas outside the occipital visual cortex and is not dependent on input from the primary visual cortex for activation. Indeed, a recent fMRI experiment has demonstrated activation in the extrastriate area in response to auditory stimuli (Bookheimer et al., 1998). Interestingly, Talairach coordinates of the $\mathrm{V} 3 \mathrm{~A}$ region determined by fMRI (Tootell et al., 1997) agree with the coordinates of the extrastriate rCBF decreases we observed in priming condition. It, however, remains to be determined whether (and how) possible nonvisual functions of regions within the extrastriate cortex are related to the priming-related rCBF reductions reported here, but the possible link seems worth considering and exploring.

As indicated by the foregoing discussion, the exact role that the extrastriate cortex plays in visual and auditory stem completion priming remains to be specified. In general, however, our findings support the conclusion that priming-related decreases in the extrastriate cortex reflect processes common to visual and auditory modalities rather than modality-specific visual processes. This conclusion is generally consistent with findings from a recent fMRI study by Buckner et al. (1999), who used a repeated word generation paradigm to examine priming effects in visual and auditory word stem completion. In their study, subjects were repeatedly presented with either visual stems or with auditory stems (in separate experiments) and generated appropriate completions. Completion latencies were reduced with repetition of the identical stems but returned to baseline levels when novel stems were presented, thus indicating that some form of item-specific priming occurred. Importantly, Buckner et al. observed repetition-related activation reductions during both visual and auditory stem completion performance in an area of the inferior temporal cortex (localized to $\mathrm{x}=-43, y=-52, z=-12$ ) near the ventral visual processing stream, anterior to the extrastriate regions discussed here. They suggested that this region is involved in amodal lexical/conceptual proc- esses that occur during both visual and auditory stem completion priming. Thus, the general conclusions from the Buckner et al. study are consistent with, and complementary to, the hypotheses that we have suggested.

One difference between the two studies is that the inferior temporal region that showed repetition-related reductions in the Buckner et al. (1999) study also showed significant activation compared to a fixation baseline, whereas, as noted earlier, the extrastriate region we have focused on was not activated significantly during the stem completion baseline compared to fixation. Differences in experimental paradigms (or possibly imaging modalities) may account for the contrasting patterns.

Although the possibility that priming-related extrastriate decreases reflect amodal processes is intriguing, the fact that we observed no extrastriate rCBF decreases during cross-modality priming-when priming depends exclusively on amodal processes-indicates that the story may be more complex (and also indicates that such decreases do not occur ubiquitously in all forms of priming). Perhaps priming-related extrastriate decreases are specific to conditions in which within-modality perceptual processes that were carried out during encoding (visual or auditory) are reinstated during a priming test. To say more at the present time would go beyond the available data. We believe that the pattern of results reported here may provide important clues concerning the nature and basis of priming, but it is evident that further studies will be required to provide a firmer basis for theoretical interpretation of our data.

Within-modality auditory priming was also associated with rCBF decreases in the right angular gyrus. This decrease may be associated with some aspect of lexical processing. Although the function of the right angular gyrus is not well understood, its activation has been reported in episodic memory tasks involving conscious recollection of words and sentences (Horwitz, Rumsey, \& Donohue, 1998; Tulving et al., 1994). Other areas that showed consistent decreases during within-modality auditory priming are the medial prefrontal cortex extending into the right anterior prefrontal cortex, and an anterior part of the precuneus (medial parietal cortex). Buckner et al. (1996) reported that both of these regions exhibited decreased activity during paired associate recall compared to a fixation control. It is possible that the decreases reported by Buckner et al. are related to our observations, but further work will be necessary to settle the matter.

Perhaps surprisingly, we did not find evidence for priming-related decreases in the primary auditory cortex or in the auditory association cortex. As noted earlier, however, in Experiment 1, we did find some evidence suggestive of priming-related decreases in the auditory association cortex. During the baseline stem completion tasks, there was significant activation in the left primary 
auditory cortex (BA 41) extending into auditory association cortex (BA 22 and 42) compared to fixation (Table 2). In primed stem completion, the primary auditory cortex activation was again observed, but the activation did not extend into the auditory association cortex. However, because the direct contrast between primed and baseline stem completion performance did not reveal significant changes in the auditory association cortex, further studies will be necessary to determine whether this region shows reliable priming-related decreases on auditory stem completion or similar tasks.

In the cross-modality condition, none of the areas that showed rCBF decreases during within-modality priming showed reduced activity; the only decrease observed in this condition was a trend in the left posterior parietal cortex (BA 39/40; angular gyrus). There were also trends for increases observed in the medial and right anterior prefrontal cortex. Although we must be cautious when interpreting these trends, they fit well with previous cognitive studies that have highlighted differences between within- and cross-modality priming. One class of explanations has focused on the idea that cross-modal priming is mediated by some form of abstract lexical representation involved in phonological input or output processing (e.g., Curran et al., 1999; Kirsner et al., 1989; Weldon, 1991). Previous neuroimaging studies have suggested that regions of the left posterior parietal cortex (BA 39/40), in the vicinity of the region that showed a decrease during cross-modal priming, are involved in phonological storage processes (Awh et al., 1996; Paulesu, Frith, \& Frackowiak, 1993). This conclusion is also supported by neuropsychological studies indicating that lesions to the left posterior parietal cortex are frequently observed in patients characterized by phonological storage deficits (Vallar \& Shallice, 1990). Thus, the trend we observed in the left posterior parietal cortex during cross-modal priming could reflect a primingrelated reduction in some aspect of phonological or lexical processing.

Activation in the right anterior prefrontal region (BA) has been observed frequently in studies of episodic or explicit memory retrieval (Tulving et al., 1994) and has been previously associated with various aspects of explicit retrieval, including retrieval "mode" (Nyberg et al., 1995), retrieval effort (Schacter et al., 1996), and postretrieval monitoring (Rugg, Fletcher, Frith, Frackowiak, \& Dolan, 1996; Schacter, Buckner, Koutstaal, Dale, \& Rosen, 1997). Two lines of evidence from behavioral studies have illuminated the role of explicit retrieval in crossmodality stem completion priming. Neuropsychological studies have demonstrated that amnesic patients show normal cross-modality priming on the stem completion task (Carlesimo, 1994; Graf, Shimamura, \& Squire, 1985), thereby indicating that explicit retrieval is not necessary for cross-modal priming to occur. Nonetheless, using process dissociation procedures previously developed by Jacoby (1991) for estimating nonconscious and con- sciously controlled contributions to retrieval, Jacoby et al. (1993) provided evidence from college students that whereas within-modality priming depends on nonconscious or implicit retrieval processes, cross-modality priming involves conscious recollection.

In a comparison of within- and cross-modality visual stem completion priming, Richardson-Klavehn and Gardiner (1996) further refined this notion by distinguishing different aspects of conscious recollection, one dimension involving intentional/unintentional retrieval and another involving awareness/unawareness of the study episode (Schacter, 1987). They provided evidence that cross-modality priming, like within-modality priming, involves unintentional retrieval of previously studied items. Richardson-Klavehn and Gardiner supported this idea by showing that a deep versus shallow encoding manipulation, which significantly affected explicit recall, had no effect on cross-modality (and within-modality) priming (see also Craik, Moscovitch, \& McDowd, 1994). Had subjects been engaging in intentional retrieval during cross-modality priming, they should have exhibited more priming after deep than shallow encoding (for elaboration of this logic, see Schacter, Bowers, \& Booker, 1989). However, Richardson-Klavehn and Gardiner also presented evidence based on Jacoby's (1991) process dissociation procedure that cross-modality priming, unlike within-modality priming, entails conscious awareness of the prior presentation of the studied words-what has been termed "involuntary conscious memory" or "involuntary explicit memory" (Schacter, 1987; Schacter et al., 1989).

If the trend for right anterior prefrontal activation in Experiment 2 reflects "involuntary explicit memory," one might expect that during cross-modal stem completion testing subjects were more likely to become aware that test items came from the study list than during within-modality stem completion testing. Informal assessments of subjects during postscan debriefing revealed that nearly all subjects (87.5\%) in both withinand cross-modality conditions were aware of the fact that some of the stems came from the study list. However, no subjects reported that they intentionally attempted to recall studied words in either condition. Future studies will thus be required to determine whether the trends for prefrontal activation observed in Experiment 2 reflect the kinds of processes observed in the foregoing cognitive studies of cross-modality priming. Moreover, because we have examined cross-modality priming of auditory stem completion after visual study, whereas the foregoing cognitive studies examined crossmodality priming of visual stem completion tasks after auditory study, it will be important to determine whether the trends observed in the present experiment are obtained in visual stem completion tasks that are preceded by auditory study. Initial results are consistent with this possibility (Schacter, Badgaiyan, \& Alpert, 1999).

In summary, the main finding from our experiments is 
that blood flow decreases in the extrastriate cortex observed previously during within-modality visual priming are also observed during within-modality auditory priming. These findings raise the possibility that extrastriate blood flow decreases reflect changes in more general priming processes than was previously suspected.

\section{METHODS}

The experimental protocol was approved by the institutional review boards of Harvard University and Massachusetts General Hospital. The experiments were conducted with young native English speaking volunteers who were right handed as assessed by Edinburgh handedness inventory (Raczkowski, Kalat, \& Nebes, 1974). All subjects had normal or corrected to normal vision and hearing. In a prescan interview, they were screened to rule out current medical conditions, history of neurological or psychiatric disturbances, prolonged use of a prescription or recreational drugs, claustrophobia, and significant prior radiation exposure. They were advised to remain alcohol free for at least $24 \mathrm{hr}$ prior to the scan.

Experiment 1 was conducted with eight young volunteers (three females, five males, 20-28 years; mean age = 25.2 years) who consented to participate for monetary compensation.

In the study phase, a list of 60 words (30 target words and 30 filler words, presented in random order), recorded in a single female voice, was presented over headphones ( $2 \mathrm{sec} /$ word). Subjects were instructed to rate the clarity of enunciation for each word on a 1 to 3 scale using a numeric keypad and responding with the right hand.

Approximately 2 min after presentation of the (nonscanned) study list, participants were scanned during separate blocks in which they provided completions to auditory word stems that could be completed with previously studied words (priming scan) or could not be completed with previously studied words (baseline scan). Thirty auditory word stems were presented (3 sec/stem; in the same female voice used for the study words) over headphones, and subjects were asked to speak aloud the first word that came to mind beginning with each stem. Participants were told to avoid proper nouns and were assured that there were no right or wrong answers. The first nine stems in each block were derived from both studied and nonstudied words. The final 21 stems in priming scans all came from the studied list, whereas in baseline scans none of the final 21 stems could be completed with a studied word. PET scans were obtained during completion of the final 20 stems. The study-test blocks were repeated so that we obtained three priming blocks and three baseline blocks. Each block comprised a different set of words and stems.

The experiment also included a fixation condition in which subjects were instructed to fixate on a crosshair.
There were two fixation blocks, one prior to the first study list and the other after the final stem completion test. Each subject thus underwent eight scans, three in the priming, three in the baseline, and two in fixation condition. During the stem completion test, responses were recorded on a tape recorder, and response latencies were recorded with a microphone connected to a PsyScope button box (Macwhinney, Cohen, \& Provost, 1997).

Target materials consisted of a list of 200 common English words, each having a unique first syllable. Selected words were divided into two lists (A and B), which were balanced according to the word frequency (range 1 to 100; Kucera \& Francis, 1967), number of syllables (range 2 to 4 ), and number of possible completions. The first syllable of each word was used as an auditory word stem, and each stem had at least six possible completions. The American Heritage College Dictionary (Costello, 1997) was used to identify syllables and determine the number of possible completions. For half of the subjects, list A was used for study lists and list B for baseline lists; for the other half, the assignment of lists to conditions was reversed. Lists A and B were further divided into three sublists that were counterbalanced across subjects, scan sequences, and priming or baseline conditions in such a way that each sublist occurred equally often in the priming and baseline condition and in each scan sequence. Further, the sequence of priming and baseline conditions was counterbalanced across subjects so that each condition occurred equally often at each scan sequence. During the stem completion task, subjects were asked to focus on a crosshair that was always displayed at the center of a computer monitor placed directly in front of the subject.

Experiment 2 was conducted with eight volunteers whose age (19 to 30 years, mean 22.75 years) and gender (three females/five males) were approximately matched to those of the subjects who participated in Experiment 1.

The experiment included both within-modality and cross-modality priming conditions. The within-modality condition was nearly identical to Experiment 1, with only two differences: (1) there were only two (instead of three) study-test blocks, and (2) during the study phase, subjects made pleasantness judgments for each study word, thus allowing us to use the same encoding task for auditory and visual study items. In the crossmodality condition, study words were presented visually at the center of a computer monitor, whereas in the within-modality condition, words were presented auditorily as described for Experiment 1. Cross-modality priming on the stem completion task is typically smaller than within-modality priming (Graf et al., 1985; Roediger \& Blaxton, 1987; Schacter \& Graf, 1989). Therefore, we attempted to create conditions that would reduce or eliminate possible differences in the overall magnitude of priming that could confound interpretation of any 
observed differences in PET activations for the two forms of priming.

Based on the results of behavioral pilot studies, we reduced the length of the study list (in each study block) from 60 words (30 study and 30 filler) for the withinmodality condition to 45 words ( 30 study and 15 filler) for the cross-modality condition. Stem completion blocks were constructed in the same manner in the within- and cross-modality conditions, as described for Experiment 1.

The words used in this experiment were selected using the criteria described for Experiment 1 and were counterbalanced across subjects in such a way that each word was used equally often in priming and baseline conditions and in within- and cross-modality conditions. The sequence of scans was also counterbalanced across subjects so that equal numbers of within- and crossmodality conditions, as well as priming and baseline conditions, occurred in each scan sequence. Each subject underwent eight scans, two in each of the four main conditions (i.e., within-modality priming and baseline, cross-modality priming and baseline).

\section{PET Scan}

During the priming, baseline, and fixation conditions head scans were obtained using a General Electric Scanditronix (Uppsala) model PC4096 15-slice whole body tomograph. An individually molded plastic face mask was used to minimize head motion during the experiment. At time zero, the stem completion or the fixation task was started along with the PET camera and continued for $90 \mathrm{sec}$. At $30 \mathrm{sec}$, radioactive tracer inhalation ( ${ }^{15} \mathrm{O}$ labeled carbon dioxide) and emission data acquisition began. Tracer inhalation and data acquisition lasted for $60 \mathrm{sec}$. A washout period of approximately 10 min was allowed between successive scans. Details of the PET facility and procedures are similar to those described earlier (Kosslyn et al., 1994).

\section{Data Analysis}

After image reconstruction, the scans from each subject were treated as follows: A correction was computed to account for head movement (rigid body translation and rotation) using a least squares fitting technique (Alpert, Berdichevsky, Levin, Morris, \& Fischman, 1996). The mean over all conditions was formed and used as input to determine the transformation to the standard coordinate system of Talairach and Tournoux (1988). This transformation was computed by deforming the $10-\mathrm{mm}$ parasagittal brain-surface contour to match the contour of a reference brain (Alpert, Berdichevsky, Weiss, Tang, Rauch, 1993). Following spatial normalization, scans were filtered with a two-dimensional Gaussian filter, full width at half maximum set to $20 \mathrm{~mm}$. Statistical analysis followed the theory of statistical parametric mapping
(Friston, Frith, Liddle, \& Frackowiak, 1991; Friston et al., 1995; Worsley, Evans, Marrett, \& Neelin, 1992). Data were analyzed with SPM95 (from the Wellcome Dept. of Cognitive Neurology, London, UK). The PET data at each voxel were normalized by the global mean and fit to a linear statistical model with cognitive state (i.e., scan condition) considered as a main effect and subjects as a block effect. Hypothesis testing was performed using the method of planned contrasts at each voxel. We set thresholds for significance according to the theory of Gaussian fields (see Friston et al., 1991; 1995; Worsley et al., 1992). When no localizing hypothesis or prior experimental data were available, a threshold of $z=4.2$ was considered significant. When we had a priori hypotheses that localized the putative activation to a specific anatomic region, we considered a threshold of $z=3.09$ to be significant. This threshold $(z=3.09)$ constitutes a compromise between a low threshold uncorrected for multiple comparisons $(z=1.96)$ and a higher threshold $(z=4.2)$ suggested by the theory of Gaussian fields for unplanned comparisons (see Worsley et al., 1996, for discussion of the basis of a lower statistical threshold for testing anatomically localized hypotheses).

\section{Acknowledgment}

This research was supported by the National Institutes of Health grant number MH57915-02 and Human Frontiers Science Program Grant number RG0126.

Reprint requests should be sent to Rajendra D. Badgaiyan, Harvard University, William James Hall, Rm. 875, 33 Kirkland Street, Cambridge, MA 02138, or via e-mail: rajendra@wjh. harvard.edu.

\section{REFERENCES}

Abdullaev, Y. G., Bechtereva, N. P., \& Melnichuk, K. V. (1998). Neuronal activity of human caudate nucleus and prefrontal cortex in cognitive tasks. Behavioral Brain Research, 97, 159-177.

Alpert, N. M., Berdichevsky, D., Levin, Z., Morris, E. D., \& Fischman, A. J. (1996). Improved methods for image registration. Neuroimage, 3, 10-18.

Alpert, N. M., Berdichevsky, D., Weiss, S., Tang, J., \& Rauch, S. L. (1993). Stereotactic transformation of PET scans by non linear least squares. In K. Uemura, T. Jones, N. A. Lassen, \& I. Kanno (Eds.), Quantification of brain function: Tracer kinetics and image analysis in PET (pp. 459463). Amsterdam: Elsevier.

Awh, E., Jonides, J., Smith, E. E., Schumacher, E. H., Koeppe, R. A., \& Katz, S. (1996). Dissociation of storage and rehearsal in verbal working memory: Evidence from positron emission tomography. Psychological Science, 7, 25-31.

Backman, L., Almkvist, O., Andersson, J., Nordberg, A., Winblad, B., Reineck, R., \& Langstrom, B. (1997). Brain activation in young and older adults during implicit and explicit retrieval. Journal of Cognitive Neuroscience, 9, 378-391.

Badgaiyan, R. D., \& Posner, M. I. (1996). Priming reduces input activity in right posterior cortex during stem completion. NeuroReport, 7, 2975-2978.

Badgaiyan, R. D., \& Posner, M. I. (1997). Time course of corti- 
cal activations in implicit and explicit recall.Journal of Neuroscience, 17, 4904-4913.

Bassili, J. N., Smith, M. C., \& MacLeod, C. M. (1989). Auditory and visual word-stem completion: Separating data-driven and conceptually driven processes. Quarterly Journal of Experimental Psychology, 41A, 439-459.

Berry, I., Demonet, J. F., Warach, S., Viallard, G., Boulanouar, K., Franconi, J. M., Marc-Vergnes, J. P., Edelman, R., \& Manelfe, C. (1995). Activation of association auditory cortex demonstrated with functional MRI. Neuroimage, 2, 215-219.

Binder, J. (1997). Functional magnetic resonance imaging. Language mapping. Neurosurgery Clinics of Nortb America, 8, 383-392.

Blaxton, T. A., Bookheimer, S. Y., Zeffiro, T. A., Figlozzi, C. M., Gaillard, W. D., \& Theodore, W. H. (1996). Functional mapping of human memory using PET: Comparisons of conceptual and perceptual tasks. Canadian Journal of Experimental Psychology 50, 42-56.

Bookheimer, S. Y., Zeffiro, T. A., Blaxton, T. A., Gaillard, W. D., Malow, B., \& Theodore, W. H. (1998). Regional cerebral blood flow during auditory responsive naming: Evidence for cross-modality neural activation. NeuroReport, 13, 2409-2413.

Buckner, R. L, Goodman, J., Burock, M., Rotte, M., Koutstaal, W., Schacter, D. L., Rosen, B., \& Dale, A. (1998). Functionalanatomic correlates of object priming in humans revealed by rapid presentation event-related fMRI. Neuron, 20, 285296.

Buckner, R. L., Koutstaal, W., Schacter, D. L., \& Rosen, B. R. (1999). Functional-anatomic evidence for amodal mechanisms underlying human repetition priming. Submitted for publication.

Buckner, R. L., Petersen, S. E., Ojemann, J. G., Miezin, F. M., Squire, L. R., \& Raichle, M. E. (1995). Functional anatomical studies of explicit and implicit memory retrieval tasks. Journal of Neuroscience, 15, 12-29.

Buckner, R. L., Raichle, M. E., Miezin, F. M., \& Petersen, S. E. (1996). Functional anatomic studies of memory retrieval for auditory words and visual picture. Journal of Neuroscience, 16, 6219-6235.

Cabeza, R., Mangels, J., Nyberg, L., Habib, R., Houle, S., McIntosh, A. R., \& Tulving, E. (1997). Brain regions differentially involved in remembering what and when: A PET study. Neuron, 19, 863-870.

Carlesimo, G. A. (1994). Perceptual and conceptual priming in amnesic and alcoholic patients. Neuropsychologia, 32, 903-921

Church, B., \& Schacter, D. L. (1994). Perceptual specificity of auditory priming: Implicit memory for voice intonation and fundamental frequency. Iournal of Experimental Psychology: Learning. Memorv and Cognition, 20, 521-533.

Cohen, M. S., Kosslyn, S. M., Breiter, H. C., DiGirolamo, G. J., Thompson, W. L., Anderson, A. K., Brookheimer, S. Y., Rosen, B. R., \& Belliveau, J. W. (1996). Changes in cortical activity during mental rotation. A mapping study using functional MRI. Brain, 119, 89-100.

Costello, R. B. (Ed.). (1997). The American Heritage College Dictionary (3rd ed.). Boston, MA: Houghton Mifflin Company.

Craik, F. I. M., Moscovitch, M., \& McDowd, J. M. (1994). Contributions of surface and conceptual information to performance on implicit and explicit memory tasks. Journal of Experimental Psychology: Learning, Memory, and Cognition, 20, 864-875.

Curran, T., Schacter, D. L., \& Galluccio, L. (1999). Cross-modal priming and explicit memory in patients with verbal production deficits. Brain and Cognition, 39, 133-146.

D'Esposito, M., Detre, J. A., Aguirre, G. K., Stallcup, M., Alsop,
D. C., Tippet, L. J., \& Farah, M. J. (1997). A functional MRI study of mental image generation. Neuropsychologia, 35, 725-30.

DeYoe, E. A., Carman, G. J., Bandettini, P., Glickman, S., Wieser, J., Cox, R., Miller, D., \& Neitz, J. (1996). Mapping striate and extrastriate visual areas in human cerebral cortex. Proceedings of the National Academy of Sciences USA, 19; 93, 2382-2386.

Fletcher, P. C., Frith, C. D., Baker, S. C., Shallice, T., Frackowiak, R. S., \& Dolan, R. J. (1995). The mind's eye-precuneus activation in memory-related imagery. Neuroimage, 2, 195-200.

Friston, K. J., Frith, C. D., Liddle, P. F., \& Frackowiak, R. S. J. (1991) Comparing functional (PET) images: The assessment of significant change. Journal of Cerebral Blood Flow and Metabolism 11, 690-699.

Friston, K. J., Holmes, A. P., Worsley, K. J., Poline, J. B., Frith, C. D., and Frackowiak, R. S. J.(1995) Statistical parametric maps in functional imaging: A general approach. Human Brain Mapping 2, 189-210.

Graf, P., Shimamura, A. P., \& Squire, L. R. (1985). Priming across modalities and priming across category levels; extending the domain of preserved functioning in amnesia. Journal of Experimental Psychology: Learning, Memory, and Cognition, 16, 164-178.

Haxby, J. V., Horwitz, B., Ungerleider, L. G., Maisog, J. M., Pietrini, P., \& Grady, C. L. (1994). The functional organization of human extrastriate cortex: A PET-rCBF study of selective attention to faces and locations. Journal of Neuroscience, 14, 6336-6353.

Horwitz, B., Rumsey, J. M., \& Donohue, B. C. (1998). Functional connectivity of the angular gyrus in normal reading and dyslexia. Proceedings of the National Academy of Sciences USA, 95, 8939-8944.

Jacoby, L. L. (1991). A process dissociation framework: Separating automatic from intentional uses of memory. Iournal of Memory and Language, 30, 513-541.

Jacoby, L. L., Toth, J. P., \& Yonelinas, A. P. (1993). Separating conscious and unconscious influences of memory: Measuring recollection. Journal of Experimental Psychology: General, 122, 139-154.

Kirsner, K., Dunn, J. C., \& Standen, P. (1989). Domain-specific resources in word recognition. In S. Lewandowsky, J. C. Dunn, \& K. Kirsner (Eds.), Implicit memory: Theoretical issues (pp. 99-122). Hillsdale, NJ: Erlbaum.

Kosslyn, S. M., Alpert, N. M., Thompson, W. L., Chabris, C. F., Rauch, S. L., \& Anderson, A. K. (1994). Identifying objects seen from different viewpoints. A PET investigation. Brain, 117, 1055-1071.

Kucera, H., \& Francis, W. N. (1967). Computational analysis of present-day American English. Providence, RI: Brown University Press.

Macwhinney, B., Cohen, J., \& Provost, J. (1997). The PsyScope experiment-building system. Spatial Vision, 11, 99-101.

McClelland, A. G. R., \& Pring, L. (1991). An investigation of cross-modality effects in implicit and explicit memory. Quarterly Journal of Experimental Psychology, 43A, 1933.

Nyberg, L., Tulving, E., Habib, R., Nilsson, L. G., Kapur, S., Houle, S., Cabeza, R., \& McIntosh, A. R. (1995). Functional brain maps of retrieval mode and recovery of episodic information. NeuroReport, 7, 249-252.

Paulesu, E., Frith, C. D., \& Frackowiak, R. S. (1993). The neural correlates of the verbal component of working memory. Nature, 362, 342-345.

Petersen, S. E., Fox, P. T., Snyder, A. Z., \& Raichle, M. E. (1990). Activation of extrastriate and frontal cortical areas by visual words and word-like stimuli. Science, 249, 1041-1044. 
Price, C. J., Wise, R. J., Warburton, E. A., Moore, C. J., Howard, D., Patterson, K., Frackowiak, R. S., \& Friston, K. J. (1996). Hearing and saying. The functional neuro-anatomy of auditory word processing. Brain, 119, 919-931.

Raczkowski, D., Kalat, J. W., \& Nebes, R. (1974). Reliability and validity of some right handed questionnaire items. Neuropsychology, 6, 43-47.

Richardson-Klavehn, A., \& Gardiner, J. M. (1996). Cross-modality priming in stem completion reflects conscious memory, but not voluntary memory. Psychonomic Bulletin and Review, 3, 238-244.

Rodman, H. R., \& Moore, T. (1997). Development and plasticity of extrastriate visual cortex in monkeys. Cerebral Cortex, 12, 639-672.

Roediger, H. L., \& Blaxton, T. A. (1987). Effects of varying modality, surface features, and retention interval on priming in word fragment completion. Memory and Cognition, 15, 379-388.

Roland, P. E., Eriksson, L., Stone-Elander, S., \& Widen, L. (1987). Does mental activity change the oxidative metabolism of the brain? Journal of Neuroscience, 7, 2373-2389.

Rugg, M. D., Fletcher, P. C., Frith, C. D., Frackowiak, R. S., \& Dolan, R. J. (1996). Differential activation of the prefrontal cortex in successful and unsuccessful memory retrieval. Brain, 119, 2073-2083.

Schacter, D. L. (1987). Implicit memory: History and current status. Journal of Experimental Psychology: Learning. Memory and Cognition, 13, 501-518.

Schacter, D. L. (1994). Priming and multiple memory systems: Perceptual mechanisms of implicit memory. In D. L. Schacter \& E. Tulving (Eds.), Memory systems 1994 (pp.233268). Cambridge, MA: MIT Press.

Schacter, D. L., Alpert, N. M., Savage, C. R., Rauch, S. L., \& Albert, M. S. (1996). Conscious recollection and the human hippocampal formation: Evidence from positron emission tomography. Proceedings of the National Academy of Sciences USA, 93, 321-325.

Schacter, D. L., Badgaiyan, R. D., \& Alpert, N. M. (1999). Visual stem completion priming within and across modalities: A PET study. NeuroReport 10, 2061-2065.

Schacter, D. L., Bowers, J., \& Booker, J. (1989). Intention, awareness, and implicit memory: The retrieval intentionality criterion. In S. Lewandowsky, J. C. Dunn, \& K. Kirsner (Eds.), Implicit memory: Theoretical issues (pp. 47-65). Hillsdale, NJ: Erlbaum.

Schacter, D. L., \& Buckner, R. L. (1998). Priming and the brain. Neuron, 20, 185-195.

Schacter, D. L., Buckner, R. L., Koutstaal, W., Dale, A. M., \& Rosen, B. R. (1997). Late onset of anterior prefrontal activity during true and false recognition: An event-related fMRI study. Neuroimage, 6, 259-269.

Schacter, D. L., Chiu, C. Y. P., \& Ochsner, K. N. (1993). Implicit memory: A selective review. Annual Review of Neuroscience, 16, 159-182.

Schacter, D. L., \& Church, B. A. (1992). Auditory priming: Implicit and explicit memory for words and voices. Journal of Experimental Psychology: Learning. Memory. and Cognition, 18, 915-930.

Schacter, D. L., \& Graf, P. (1989). Modality specificity of im- plicit memory for new associations. Journal of Experimental Psychology: Learning, Memory, and Cognition., 15, 312.

Shulman G. L., Fiez J. A., Corbetta M., Buckner R. L., Miezin F. M., Raichle M. E., \& Petersen, S. E. (1997). Common blood flow changes across visual tasks. II. Decreases in cerebral cortex. Iournal of Cognitive Neuroscience, 9, 648-663.

Squire, L. R., Ojemann, J. G., Miezin, F. M., Petersen, S. E., Videen, T. O., \& Raichle, M. E. (1992). Activation of the hippocampus in normal humans: A functional anatomical study of memory. Proceedings of National Academy of Sciences. USA, 89, 1837-1841.

Squire, L. R. (1994). Declarative and nondeclarative memory: Multiple brain systems supporting learning and memory. In D. L. Schacter \& E. Tulving (Eds.), Memory Systems 1994 (pp. 203-231). Cambridge, MA: MIT Press.

Strainer, J. C., Ulmer, J. L., Yetkin, F. Z., Haughton, V. M., Daniels, D. L., \& Millen, S. J. (1997). Functional MR of the primary auditory cortex: An analysis of pure tone activation and tone discrimination. American Journal of Neuroradiology, 18, 601-610.

Talairach, J., \& Tournoux, P. (1988). Co-planar stereotaxic atlas of the buman brain. New York: Thieme.

Tanenhaus, M. K., Flanagan, H. P., \& Seidenberg, M. S. (1980). Orthographic and phonological activation in auditory and visual word recognition. Memory and Cognition, 8, 513520.

Tootell, R. B., Mendola, J. D., Hadjikhani, N. K., Ledden, P. J., Liu, A. K., Reppas, J. B., Sereno, M. I., \& Dale, A. M. (1997). Functional analysis of $\mathrm{V} 3 \mathrm{~A}$ and related areas in human visual cortex. Journal of Neuroscience, 17, 7060-7078.

Tulving, E., Kapur, S., Moscovitch, M., Craik, F. I., Habib, R., \& Houle, S. (1994). Neuroanatomical correlates of retrieval in episodic memory: Auditory sentence recognition. Proceedings of National Academy of Sciences, USA, 91, 20122015.

Tulving, E., \& Schacter, D. L. (1990). Priming and human memory systems. Science, 247, 301-306.

Vallar, G., \& Shallice, T. (Eds.) (1990). Neuropsychological impairments of short-term memory. New York: Cambridge University Press.

Weldon, M. S. (1991). Mechanisms underlying priming on perceptual tests. Journal of Experimental Psychology: Learning. Memory and Cognition, 17, 526-541.

Wiggs, C. L., \& Martin, A. (1998). Properties and mechanisms of perceptual priming. Current Opinion in Neurobiology 8, 227-233.

Worsley, K. J., Evans, A. C., Marrett, S., \& Neelin, P. (1992) A three-dimensional statistical analysis for $\mathrm{rCBF}$ activation studies in human brain. Journal of Cerebral Blood Flow and Metabolism, 12, 900-918.

Worsley, K. J., Marrett, S., Neelin, P., Vandal, A. C., Friston, K. J., \& Evans, A. C. (1996). A unified statistical approach for determining significant signals in images of cerebral activation. Human Brain Mapping, 4, 58-73.

Zilles, K., \& Clarke, S. (1997). Architecture, connectivity, and transmitter receptors of human extrastriate visual cortex. Cerebral Cortex, 12, 673-742. 


\section{This article has been cited by:}

1. Noa Tal, Amir Amedi. 2009. Multisensory visual-tactile object related network in humans: insights gained using a novel crossmodal adaptation approach. Experimental Brain Research 198:2-3, 165-182. [CrossRef]

2. Samuel T. Moulton, Stephen M. Kosslyn. 2008. Using Neuroimaging to Resolve the Psi DebateUsing Neuroimaging to Resolve the Psi Debate. Journal of Cognitive Neuroscience 20:1, 182-192. [Abstract] [PDF] [PDF Plus]

3. Samuel T. Moulton, Stephen M. Kosslyn. 2008. Using Neuroimaging to Resolve the Psi Debate. 20:1, 182. [CrossRef]

4. Pierre Gagnepain, Karine Lebreton, Francis Eustache. 2007. À la recherche d'une mémoire perceptive pour la forme auditive des mots : apport des études sur l'amorçage perceptif. L'Année psychologique 106:04, 543. [CrossRef]

5. Uri Hasson, Howard C. Nusbaum, Steven L. Small. 2006. Repetition Suppression for Spoken Sentences and the Effect of Task DemandsRepetition Suppression for Spoken Sentences and the Effect of Task Demands. Journal of Cognitive Neuroscience 18:12, 2013-2029. [Abstract] [PDF] [PDF Plus]

6. Ingo G. Meister, Jürgen Weidemann, Henrik Foltys, Henning Brand, Klaus Willmes, Timo Krings, Armin Thron, Rudolf Töpper, Babak Boroojerdi. 2005. The neural correlate of very-long-term picture priming. European Journal of Neuroscience 21:4, 1101-1106. [CrossRef]

7. Daniel L. Schacter, Ian G. Dobbins, David M. Schnyer. 2004. Specificity of priming: a cognitive neuroscience perspective. Nature Reviews Neuroscience 5:11, 853-862. [CrossRef]

8. Luigi Maccotta, Randy L. Buckner. 2004. Evidence for Neural Effects of Repetition that Directly Correlate with Behavioral PrimingEvidence for Neural Effects of Repetition that Directly Correlate with Behavioral Priming. Journal of Cognitive Neuroscience 16:9, 1625-1632. [Abstract] [PDF] [PDF Plus]

9. Dafna Bergerbest, Dara G. Ghahremani , John D. E. Gabrieli . 2004. Neural Correlates of Auditory Repetition Priming: Reduced fMRI Activation in the Auditory CortexNeural Correlates of Auditory Repetition Priming: Reduced fMRI Activation in the Auditory Cortex. Journal of Cognitive Neuroscience 16:6, 966-977. [Abstract] [PDF] [PDF Plus]

10. Paul J. Laurienti, Mark T. Wallace, Joseph A. Maldjian, Christina M. Susi, Barry E. Stein, Jonathan H. Burdette. 2003. Cross-modal sensory processing in the anterior cingulate and medial prefrontal cortices. Human Brain Mapping 19:4, 213-223. [CrossRef]

11. E. Darcy Burgund, Chad J. Marsolek, Monica Luciana. 2003. Serotonin levels influence patterns of repetition priming. Neuropsychology 17:1, 161-170. [CrossRef]

12. Rajendra D. Badgaiyan, Daniel L. Schacter, Nathaniel M. Alpert. 2003. Priming of new associations: a PET study. 14:18, 2475. [CrossRef]

13. Frank Jessen, Christoph Manka, Lukas Scheef, Dirk-Oliver Granath, Hans H. Schild, Reinhard Heun. 2003. Novelty detection and repetition suppression in a passive picture viewing task: A possible approach for the evaluation of neuropsychiatric disorders. Human Brain Mapping 17:4, 230-236. [CrossRef]

14. YalDin Abdullaev, Barbara L. Kennedy, Allan Tasman. 2002. Changes in neural circuitry of language before and after treatment of major depression. Human Brain Mapping 17:3, 156-167. [CrossRef]

15. H??l??ne Gros, Kader Boulanouar, G??rard Viallard, Emmanuelle Cassol, Pierre Celsis. 2001. Event-Related Functional Magnetic Resonance Imaging Study of the Extrastriate Cortex Response to a Categorically Ambiguous Stimulus Primed by Letters and Familiar Geometric Figures. Journal of Cerebral Blood Flow \& Metabolism 1330-1341. [CrossRef]

16. Karine Lebreton, Béatrice Desgranges, Brigitte Landeau, Jean-Claude Baron, Francis Eustache. 2001. Visual Priming Within and Across Symbolic Format Using a Tachistoscopic Picture Identification Task: A PET StudyVisual Priming Within and Across Symbolic Format Using a Tachistoscopic Picture Identification Task: A PET Study. Journal of Cognitive Neuroscience 13:5, 670-686. [Abstract] [PDF] [PDF Plus]

17. Lars Nyberg. 2000. Perceptual priming and extrastriate cortex: Consensus and controversy. Human Brain Mapping 10:4, 195-196. [CrossRef]

18. Rajendra D. Badgaiyan. 2000. Neuroanatomical organization of perceptual memory: An fMRI study of picture priming. Human Brain Mapping 10:4, 197-203. [CrossRef]

19. Rajendra D. Badgaiyan. 2000. Executive control, willed actions, and nonconscious processing. 9:1, 38. [CrossRef] 